\title{
The unusual amino acid L-ergothioneine is a physiologic cytoprotectant
}

\author{
BD Paul ${ }^{1}$ and SH Snyder*,1,2,3
}

Ergothioneine (ET) is an unusual sulfur-containing derivative of the amino acid, histidine, which is derived exclusively through the diet. Although ET was isolated a century ago, its physiologic function has not been clearly established. Recently, a highly specific transporter for ET (ETT) was identified in mammalian tissues, which explains abundant tissue levels of ET and implies a physiologic role. Using RNA interference, we depleted cells of its transporter. Cells lacking ETT are more susceptible to oxidative stress, resulting in increased mitochondrial DNA damage, protein oxidation and lipid peroxidation. ETT is concentrated in mitochondria, suggesting a specific role in protecting mitochondrial components such as DNA from oxidative damage associated with mitochondrial generation of superoxide. In combating cytotoxic effects of pyrogallol, a known superoxide generator, ET is as potent as glutathione. Because of its dietary origin and the toxicity associated with its depletion, ET may represent a new vitamin whose physiologic roles include antioxidant cytoprotection.

Cell Death and Differentiation (2010) 17, 1134-1140; doi:10.1038/cdd.2009.163; published online 13 November 2009

L-ergothioneine (ET) is an unusual sulfur-containing amino acid discovered a century ago in the rye ergot. ${ }^{1}$ The only organisms known to synthesize it are bacteria belonging to the order Actinomycetales (example mycobacteria) and non-yeast like fungi which include members of the division Basidiomycota and Ascomycota. ${ }^{2,3}$ These microbes synthesize ET from Lhistidine via an intermediate hercynine, a betaine of histidine. ${ }^{4,5}$ A sulfur group is added to hercynine to form ET. ${ }^{4}$ The biosynthetic enzymes catalyzing these reactions are unknown.

ET is widely distributed in both the plant and animal kingdoms. Mammals acquire ET solely through their diet. Foods such as mushrooms, black beans, red meat and oats are rich in ET. ${ }^{6,7}$ Plants accumulate ET from the soil where microbes generate it. ET is concentrated in cells and tissues frequently exposed to oxidative stress with highest levels in the millimolar range occurring in blood, lens of the eye, liver, bone marrow and seminal fluid..$^{8-10}$

ET is tautomeric and exists predominantly in the thione form in neutral aqueous solutions which may account for ET's resistance to autooxidation, ${ }^{11}$ in contrast to glutathione, the other major water-soluble thiol which is rapidly oxidized. ET's sulfhydryl group implies an antioxidant role. ${ }^{8-11}$ Exogenous ET can scavenge reactive oxygen and nitrogen species and protect cells from a variety of apoptotic insults. Earlier studies of ET's antioxidant actions have been conducted in vitro or using overexpression systems with no evidence for a physiologic function.

An important advancement in understanding ET physiology was the discovery by Schomig and associates that the putative transporter protein OCTN1, a product of the gene SLC22A4 (solute carrier family 22, member 4 ) that had been implicated in rheumatoid arthritis, is primarily a physiologic ET transporter (ETT). ${ }^{12}$ This transporter was first cloned and characterized earlier in 1997 and shown to transport organic cations such as tetraethyl ammonium, carnitine, and verapamil. ${ }^{13}$ Using a liquid chromatography mass spectroscopy difference shading approach, Schomig and colleagues showed a very high specificity for ET. ${ }^{12-14}$ ETT occurs in a variety of tissues, ${ }^{12-15}$ with a high level of expression in the cells of the hematopoietic lineage and CD14 ${ }^{+}$cells, such as monocytes and macrophages. ${ }^{12-16}$ Levels of the transporter correlate closely with those of ET. Mutations in the ET transporter locus have been identified as susceptibility factors for autoimmune disorders such as rheumatoid arthritis and Crohn's disease. ${ }^{17,18}$ Interestingly, the gene for ETT lies in close proximity to genes involved in inflammatory responses such as caspase recruitment domain family, member 15, CARD 15. ETT is abundantly expressed in $\mathrm{CD}_{14}{ }^{+}$macrophages and monocytes consistent with a role in inflammation. ${ }^{12-19}$

ET inhibits tumor necrosis factor- $\alpha$-induced release of the inflammatory cytokine interleukin-8 (IL-8) in alveolar macrophages. ${ }^{20}$ ETT expression is upregulated by inflammatory cytokines. ${ }^{17-21}$ The transcription factor nuclear factor-kappa $B$, which regulates inflammatory genes, has binding sites in the promoter of human ETT and regulates its expression, further supporting a role for ETT in modulating inflammatory processes. ${ }^{21}$ Patients with rheumatoid arthritis accumulate ET in their synoviocytes. ETT influences cell proliferation and

\footnotetext{
${ }^{1}$ The Solomon H. Snyder Department of Neuroscience, Johns Hopkins University School of Medicine, Baltimore, MD 21205, USA; ${ }^{2}$ Department of Psychiatry and Behavioral Sciences, Johns Hopkins University School of Medicine, Baltimore, MD 21205, USA and ${ }^{3}$ Department of Pharmacology and Molecular Sciences, Johns Hopkins University School of Medicine, Baltimore, MD 21205, USA

${ }^{*}$ Corresponding author: SH Snyder, The Solomon H. Snyder Department of Neuroscience, 725 N. Wolfe St, Johns Hopkins University School of Medicine, Baltimore, MD 21205, USA. Tel: 410955 3024; Fax: 410955 3623; E-mail: ssnyder@jhmi.edu

Keywords: histidine derivative; antioxidant; superoxide; mitochondrial DNA; reactive oxygen species

Abbreviations: ET, ergothioneine; ETT, ergothioneine Transporter; DNPH, 2,4-dinitrophenylhydrazine; MDA, malondialdehyde; mtDNA, mitochondrial DNA; MTT, 3-(4, 5-dimethylthiazol-2-yl)-2,5-diphenyltetrazolium bromide; OCTN1, novel organic cation transporter 1; TBARS, thiobarbituric acid reactive substances

Received 06.8.09; revised 21.9.09; accepted 29.9.09; Edited by RA Knight; published online 13.11.09
} 
differentiation ${ }^{22}$ and treatment of intestinal Caco-2 cells with ET stimulates cell proliferation. ${ }^{23}$ ETT is also one of the genes upregulated during liver regeneration.

Although ET is not made by the body, it is taken up from the diet and retained preferentially in cells exposed to oxidative stress and involved in inflammatory responses. The presence of a high affinity transporter in conjunction with its non-random distribution implies physiologic function. In this study, we depleted endogenous ETT in HeLa cells and show marked augmentation of oxidative stress and cell death providing strong evidence for a physiological role of ET as a physiological antioxidant.

\section{Results}

RNAi-mediated knockdown of the ergothioneine transporter ETT/OCTN1. We examined a range of cell lines for ETT. HeLa cells, RAW 264.7, HaCaT cells and PC12 cells express ETT and transport ET. We focused on HeLa cells, because this cell line is especially amenable to transfection. We used RNA interference to deplete ETT, which resulted in approximately $75 \%$ depletion as confirmed by reverse transcriptase PCR (Figure 1a and c). Western blot analysis also revealed a similar decrease in the ETT protein. Depletion of ETT was also verified by measuring the uptake of $\left[{ }^{3} \mathrm{H}\right] \mathrm{ET}$. In HeLa cells transfected with ETT siRNA, transport of ET was reduced by $75 \%$ (Figure 1d). Loss of ET transport was directly proportional to the degree of depletion of ETT mRNA.

ETT-depleted cells are more sensitive to oxidative stress. ETT depletion resulted in a decrease in cell proliferation (data not shown), consistent with earlier studies. $^{22,23}$ If ET is a physiological antioxidant, depletion of its transporter should result in the decreased ability of cells to cope with oxidative stress. ET protected against hydrogen peroxide-mediated toxicity (Figure $2 \mathrm{a}$ ). In unprotected HeLa cells, hydrogen peroxide $(0.5 \mathrm{mM})$ induced apoptosis, whereas pretreatment with $1 \mathrm{mM}$ ET for $24 \mathrm{~h}$ was protective. ETT-deficient cells were more susceptible to hydrogen peroxide, with or without pretreatment by ET (Figure $2 b$ ). The extent of reduced protection correlated with the extent of ETT depletion. The RNAi-mediated depletion was not total, hence the residual transporter present was able to afford a small degree of protection. The augmented cytotoxicity associated with ETT depletion indicates that basal levels of ET provide physiologic cytoprotection.

ETT depletion differentially impacts protein and lipid oxidation. Glutathione, which is hydrophilic, preferentially prevents oxidation of water-soluble proteins, whereas the lipophilic bilirubin selectively protects lipids from peroxidation. ${ }^{24}$ Might the hydrophilic ET differentially affect protein and lipid oxidation? Protein carbonylation, a common oxidative modification induced by free radicals, can be detected using 2,4-dinitrophenylhydrazine (DNPH), which reacts with protein carbonyls generated by oxidants. The DNPH conjugated proteins can then be detected and quantitated using an anti-DNPH antibody. Cells depleted of ETT displayed increased levels of protein carbonylation (Figure 3a, compare black bars to gray). ET pretreatment protected control but not ETT-depleted cells (Figure $3 a$ ). Lipid peroxidation in these cells was also monitored. In this case, cells were treated with a mixture of hydrogen peroxide and ferrous sulfate to generate hydroxyl radical by the
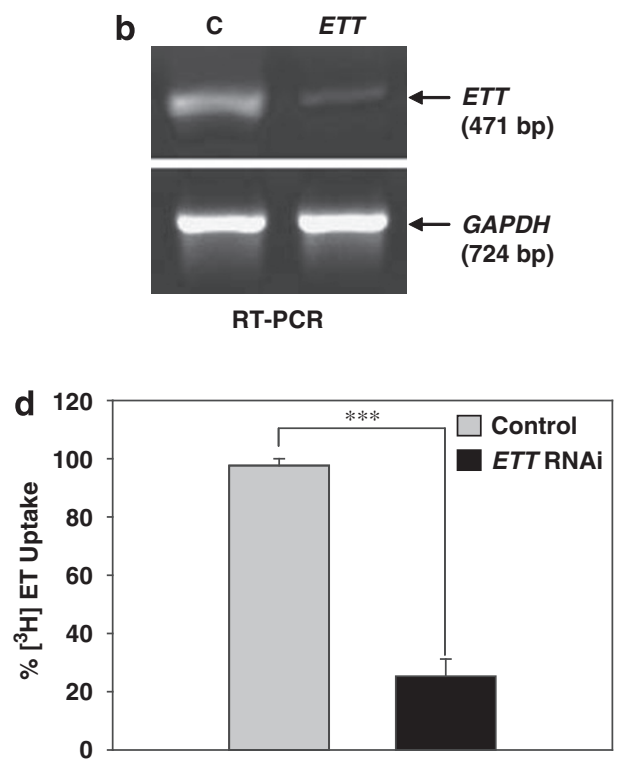

Figure 1 (a) Structure of L-Ergothioneine: ET is a betaine of the amino acid histidine with a sulfhydryl group attached to the carbon of the imidazole ring. (b) ETT knockdown in HeLa cells. Total RNA was isolated from control and RNAi-transfected cells and $500 \mathrm{ng}$ of RNA was used for the RT-PCR. The top panel shows the RT-PCR product corresponding to the ETT transcript. The bottom panel shows the levels of the GAPDH transcript used as an endogenous loading control. (c) A quantitative representation of the gel shown in B, which shows approximately $75 \%$ knockdown of the ETT transcript. (d) $\left[{ }^{3} \mathrm{H}\right]$ Ergothioneine uptake assay was performed essentially as described earlier. At $72 \mathrm{~h}$ post transfection, cells were incubated with $3 \mu \mathrm{M} \mathrm{ET}$ for an hour at $37^{\circ} \mathrm{C}$ and uptake monitored. The RNAi-depleted cells show about $75 \%$ decrease in ET uptake compared with the control cells. The data shown are the mean \pm S.E. of three independent experiments ${ }^{* \star *} P<0.001$ using the Student's $t$-test 
Fenton reaction to induce lipid peroxidation. ETT-depleted cells displayed enhanced lipid peroxidation monitored by the thiobarbituric acid reactive substances (TBARS) assay (Figure $3 b$ ). The increase in lipid peroxidation following ETT depletion was less than the augmentation in protein oxidation, fitting with the notion that the hydrophilic ET selectively protects water-soluble proteins.

ET protects cellular DNA from damage induced by reactive oxygen species. ETT is abundantly expressed in mitochondria. ${ }^{25}$ Mitochondrial DNA is especially vulnerable to stress, because unlike nuclear DNA, there are no histones to protect it. Mitochondria also lack the very efficient DNA
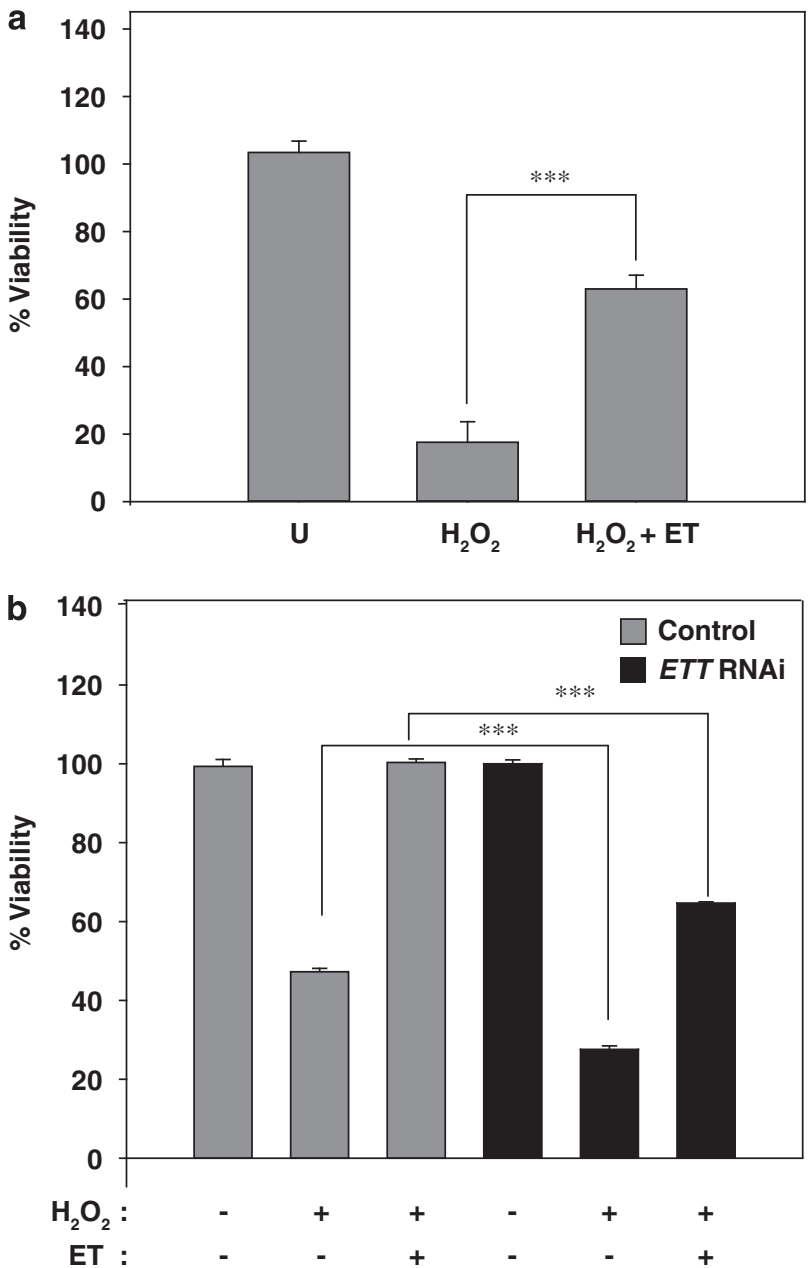

Figure 2 Ergothioneine protects against apoptosis induced by hydrogen peroxide. (a) Cultured HeLa cells were treated with $1 \mathrm{mM}$ hydrogen peroxide for $16 \mathrm{~h}$ after a 24-h pretreatment with $1 \mathrm{mM}$ ET and assayed for cell viability using the MTT Assay. Data are expressed as percentage of viability compared with untreated (designated as $\mathrm{U}$ ) cells. The ET-treated cells are better protected against $\mathrm{H}_{2} \mathrm{O}_{2}$ toxicity. Data shown are means $\pm S$.E. of five independent experiments, ${ }^{* * *} P<0.001$ using Student's $t$-test. (b) Depletion of the ETT RNA results in increased apoptosis in response to $\mathrm{H}_{2} \mathrm{O}_{2}$. Cells were transfected with ETT siRNA and $72 \mathrm{~h}$ post transfection, treated with or without $1 \mathrm{mM}$ ET for $24 \mathrm{~h}$ and then challenged with $0.5 \mathrm{mM} \mathrm{H}_{2} \mathrm{O}_{2}$ for $16 \mathrm{~h}$. Results are expressed as percentage of viability compared with control, untreated cells. The ETT-depleted cells (black bars) were more susceptible to oxidative stress and showed a marked decrease in viability, $P<0.001$ using Student's $t$-test repair mechanisms of the nucleus. The electron transport chain of mitochondria generates free radicals and ROS, such as superoxide and hydroxyl radical that create redox imbalance. In the process, mitochondrial DNA itself is targeted by ROS leading to DNA nicks, breaks and mutations. A region of the mtDNA, the Displacement or D-loop, is a hotspot for DNA damage. Several mutations occurring here are associated with cancers. ${ }^{26}$ Damaged DNA is a poor template for PCR amplification so that the extent of damage is reflected in the degree of amplification, which can be precisely measured. $^{27-29}$ To determine whether ET can protect mtDNA
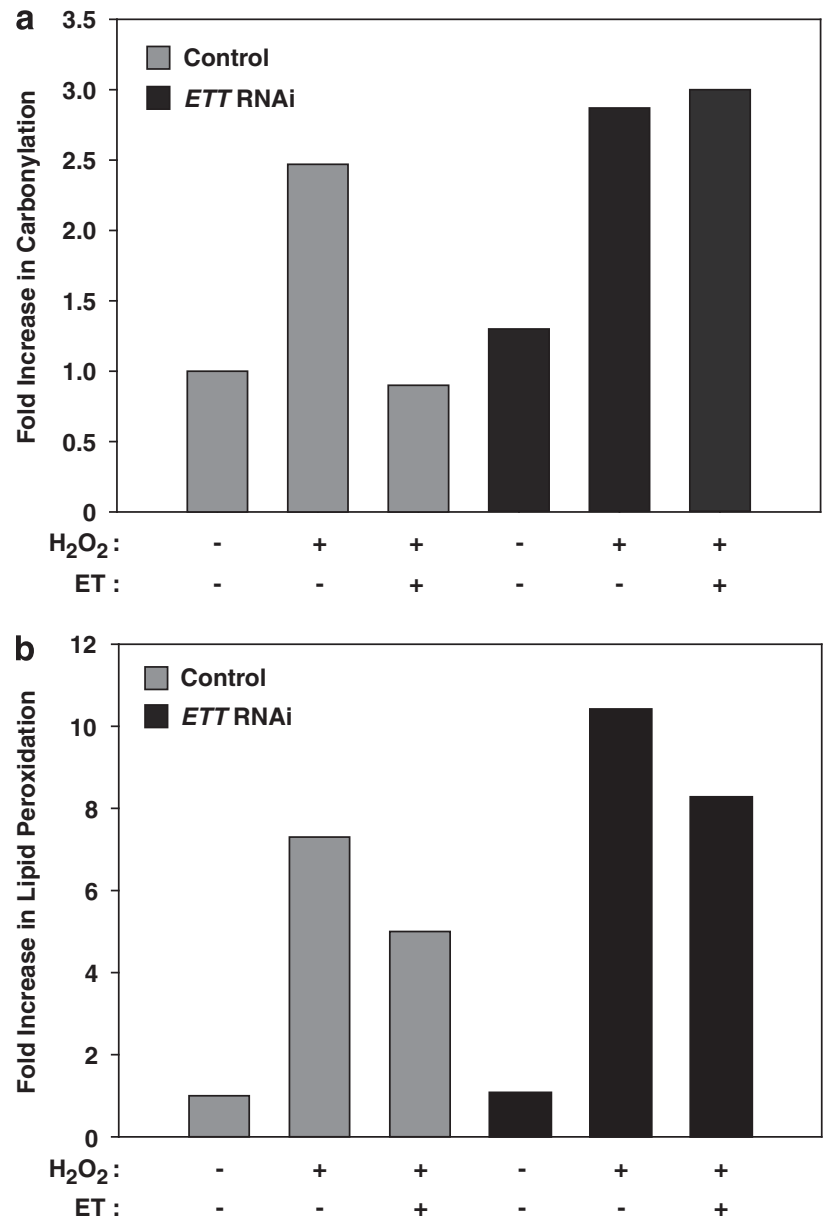

Figure 3 Depletion of the ET transporter leads to increased damage to cellular proteins and lipids. (a) Control- and ETT-depleted HeLa cells were treated with $0.5 \mathrm{mM} \mathrm{H}_{2} \mathrm{O}_{2}$ or $16 \mathrm{~h}$ after preincubation with $1 \mathrm{mM} \mathrm{ET}$ and assayed for protein oxidation using 2,4-dinitrophenylhydrazine (DNPH), which reacts with protein carbonyl groups generated by oxidation. The DNPH-derivatized samples were electrophoresed and subjected to western blotting using anti-DNPH antibodies. The signals were quantified using densitometry and expressed as a fold increase in protein carbonylation compared with the untreated control. The data shown are from a representative experiment repeated at least three times. The ETT-depleted cells (black bars) show higher levels of oxidation compared with control cells (gray bars). (b) ETT cells show a higher level of lipid peroxidation. Cells were pretreated with $1 \mathrm{mM}$ ET $72 \mathrm{~h}$ post transfection and lipid peroxidation induced using a mixture of $30 \mu \mathrm{M} \mathrm{FeSO}_{4}$ and $100 \mu \mathrm{M} \mathrm{H}_{2} \mathrm{O}_{2}$ for $2 \mathrm{~h}$ at $37^{\circ} \mathrm{C}$. The cells were then assayed using the Thiobarbituric Acid Reactive Substances (TBARS) Assay to quantify the levels of Malondialdehyde (MDA), which is a product of lipid peroxidation. The ETTdepleted cells undergo higher oxidation than control cells (Black versus gray bars). Data shown is a representative of three independent experiments 
a

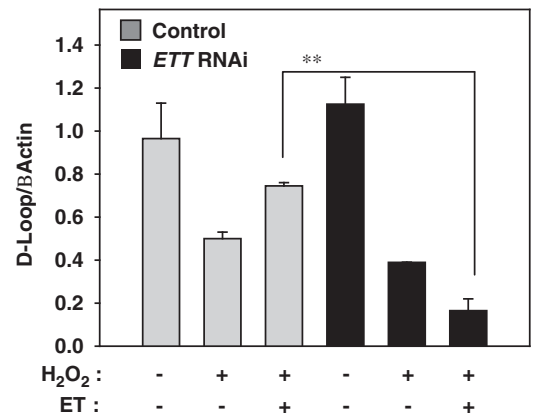

b

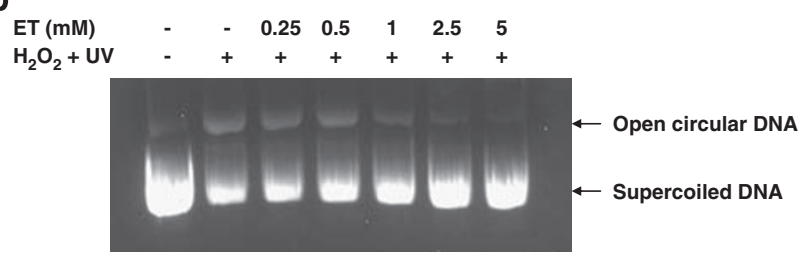

Figure 4 Ergothioneine prevents DNA damage. (a) ET protects mitochondrial DNA (mtDNA) from damage induced by reactive oxygen species. Control and ETT cells were treated with $0.5 \mathrm{mM} \mathrm{H}_{2} \mathrm{O}_{2}$ for $4 \mathrm{~h}$ with or without pretreatment with $1 \mathrm{mM}$ ET for $24 \mathrm{~h}$, and total DNA (genomic and mitochondrial) were isolated. Ten nanograms of the DNA were used as a template for quantitative real-time PCR (qPCR) using probes specific for the D-loop, a hotspot for mtDNA damage and normalized to $\beta$-actin, the probe for nuclear DNA. The ETT RNAi-transfected cells (black bars) yielded a decreased signal in the PCR, indicating increased DNA damage even in the presence of ET. The control cells were more resistant to mtDNA damage (gray bars). The data shown are the mean of duplicates of three independent experiments, which yielded similar results. ${ }^{*}$ indicates $p<0.01$ by Students $t$ test. (b) ET prevents nicking induced by UV and $\mathrm{H}_{2} \mathrm{O}_{2}$. Supercoiled plasmid DNA $(1 \mu \mathrm{g})$ was treated with $2.5 \mathrm{mM} \mathrm{H}_{2} \mathrm{O}_{2}$ in the presence of increasing concentrations of ET $(0.25-5 \mathrm{mM})$, irradiated at $254 \mathrm{~nm}$ for $5 \mathrm{~min}$ and electrophoresed on a $1 \%$ agarose gel in $1 \times$ Tris Acetate EDTA (TAE). The lower band represents supercoiled plasmid DNA. The more slowly migrating band is the open circular DNA arising from nicking of DNA. ET protects against this oxidative stress in a dose-dependent manner

from oxidative stress, we stressed cells with hydrogen peroxide. We then isolated total DNA and assessed the degree of mtDNA damage using quantitative real-time PCR (Figure 4a). ET exposure protected DNA in control but not in ETT-depleted cells. To assess whether ET can directly protect against DNA damage, we treated supercoiled plasmid DNA with $2.5 \mathrm{mM}$ hydrogen peroxide and irradiated with UV for $5 \mathrm{~min}$ in the presence of increasing concentrations of ET $(0.25-5 \mathrm{mM})$. ET prevented DNA nicking by the $\mathrm{UV} /$ hydrogen peroxide mixture in a dose-dependent manner (Figure 4b). ET can scavenge hydroxyl radicals as well as directly absorb UV radiation to block its effects on DNA. ET has an absorption spectrum in the UV range similar to DNA with a molar extinction coefficient of $1.4 \times 10^{-4} \mathrm{M}^{-1} \mathrm{~cm}^{-1}$, $\lambda_{\max } 257$, suggesting that ET can act as a physiological UV filter. $^{30}$

In vitro and cell culture studies have identified ET as a superoxide scavenger. ${ }^{31}$ We treated HeLa cells with pyrogallol $(150 \mu \mathrm{M})$, a known generator of superoxide. Cells incubated with ET exhibited higher growth rates and less apoptosis than untreated cells. ET protected the cells from pyrogallol-generated stress in a dose-dependent manner (Figure 5a). ETT depletion markedly augmented sensitivity to pyrogallol-induced cell damage and death, reinforcing the physiologic antioxidant role of endogenous ET (Figure 5c and d). Pretreatment with ET did not prevent morphological damage in ETT-depleted cells (Figure 5c compare bottom panel with the top).

The abundant evidence that endogenous ET serves an antioxidant role, especially for water-soluble cellular constituents, implies a physiological role comparable with other watersoluble antioxidants. Accordingly, we compared ET with ascorbate and glutathione, the other major water-soluble antioxidants. ET was somewhat more active than the other two substances in preventing pyrogallol-induced cell death (Figure 5b).

\section{Discussion}

This study provides substantial evidence that ET is a physiologic antioxidant cytoprotectant. ET tissue levels are maintained by its transporter, ETT. Depletion of ETT by RNA interference prevents the antioxidant actions of exogenous ET. More importantly, in the absence of added ET, ETT depletion leads to enhanced oxidative damage of protein, lipid and DNA as well as augmented cell death. In these studies the incubation media contained very low concentrations of ET so that cytoprotection was afforded by 'endogenous' ET accumulated by the cells.

Our findings that exogenous ET exerts antioxidant, cytoprotective effects fits with observations of others. ${ }^{32-35}$ Schomig and associates observed ET protection against cytotoxicity elicited by $\mathrm{Cu}^{2+}$ but not hydrogen peroxide, hydroxynonenal, doxyrubicin, iron(II)/ascorbic acid and sodium nitrite. ${ }^{7}$ In these experiments, cells were only exposed to ET for an hour. Because of ET's slow rate of accumulation, maximal effects require prolonged exposure. ${ }^{35}$ This study is the first to show the endogenous antioxidant capacity of ET using RNA interference in cells naturally expressing ETT.

In protecting against cell death ET was somewhat more active than the same concentrations of added ascorbate or glutathione. Endogenous levels of ET vary, attaining millimolar concentrations in tissues that are typically exposed to marked oxidative stress such as blood cells, the lens of the eye, liver and bone marrow. In the bovine lens, ET concentrations, about $7 \mathrm{mM},{ }^{10}$ exceed those of glutathione, generally regarded as the most abundant endogenous antioxidant. In the bovine cornea, ET concentrations are 14-fold higher than those of glutathione, suggesting that it is the principal antioxidant in this tissue. ${ }^{10} \mathrm{ET}$ is avidly retained in cells and its tissue concentrations tend to be stable. When acting as an antioxidant, its $\mathrm{SH}$ group is oxidized but very rapidly reduced because of the unique tautomeric structure of the molecule. By contrast, glutathione is often almost totally depleted in the face of oxidative stress

Varying properties of diverse antioxidants may lead to different functions. Bilirubin is unique in that its low-tissue concentrations in the $50 \mathrm{nM}$ range, exert cytoprotection comparable with glutathione, which is thousands of times more abundant. ${ }^{36}$ When bilirubin acts as an antioxidant, it is itself oxidized to biliverdin. Biliverdin reductase rapidly reduces biliverdin back to bilirubin with this enzymatic cycling providing more than 1000-fold amplification of bilirubin potency. ${ }^{37}$ 

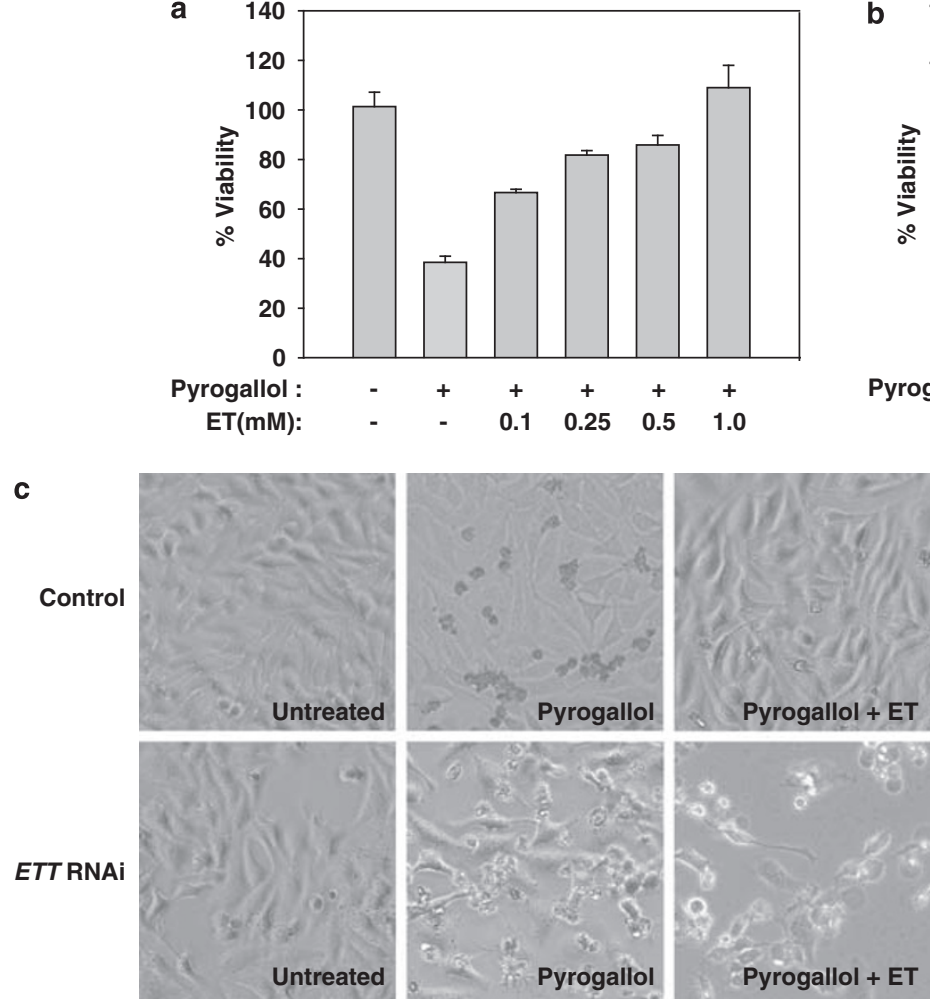

b
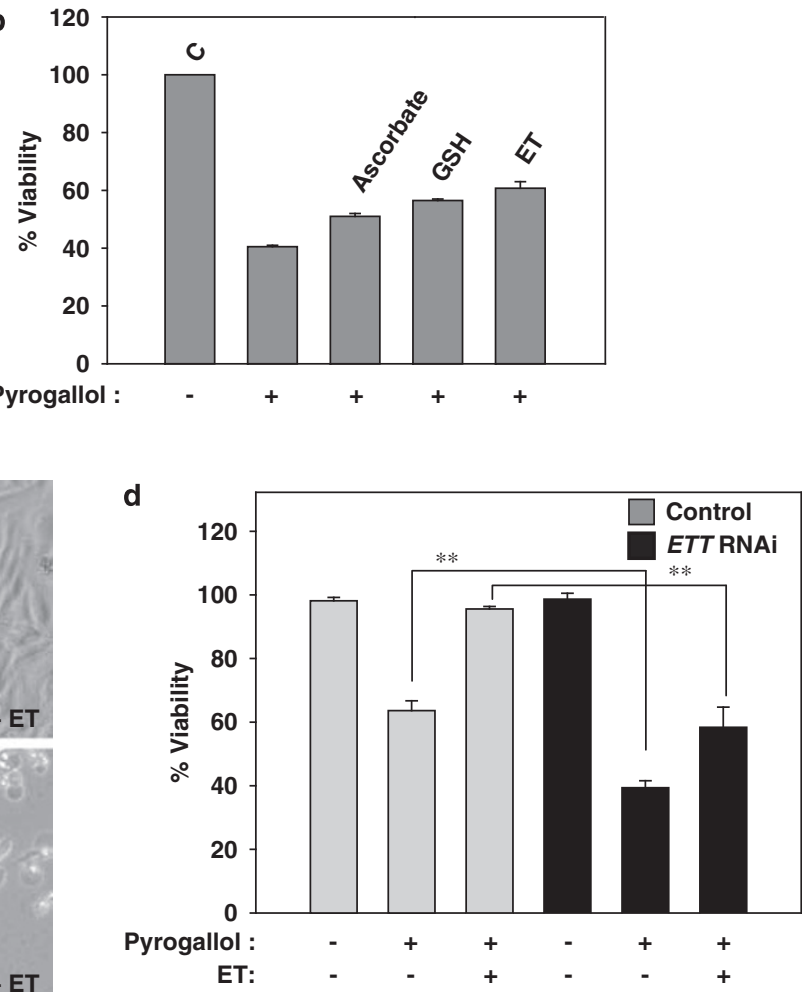

Figure 5 Ergothioneine protects HeLa cells against pyrogallol, a superoxide generator. (a) HeLa cells were treated with $150 \mu \mathrm{M}$ pyrogallol for $16 \mathrm{~h}$ in the presence of increasing concentrations of ET (0.1-1 mM). ET-protected cells in a dose-dependent manner. (b) Comparison of ET with other water-soluble antioxidants such as glutathione and ascorbate $(0.1 \mathrm{mM}$ each). ET was marginally better than the antioxidants glutathione and ascorbate in protecting against pyrogallol-induced cytotoxicity. (c) Morphology of control and ETT cells treated with pyrogallol. RNAi-depleted cells (shown in the bottom panel) undergo severe morphological deformation such as cell shrinkage and membrane blebbing whereas control cells (top panel) retain their normal cellular architecture. (d) MTT Cell viability assays reveal that control cells (gray bars) are more resistant to pyrogallol-induced damage. Data show mean \pm S.E. and are derived from three independent experiments, ${ }^{* \star} P<0.01$

Antioxidants differ in their selectivity for various classes of molecules. The hydrophilic ascorbate and glutathione protect against damage to water-soluble proteins, whereas the lipophilic bilirubin preferentially protects against lipid peroxidation. ${ }^{24}$ Thus, abrogation of the biliverdin-bilirubin amplification cycle by depletion of biliverdin reductase selectively increases lipid peroxidation, whereas depletion of glutathione selectively augments the oxidation of water-soluble proteins. ${ }^{24} \mathrm{ET}$ is highly water soluble and appears to prevent carbonylation of water-soluble proteins resembling the actions of glutathione.

ETT is highly concentrated in the plasma membrane and mitochondria. Because of the absence of antibodies for ET that are suitable for immunohistochemistry, its detailed intracellular localization has not been established. However, following administration of radiolabeled ET to rats, mitochondrial accumulation was higher than in any other particulate subcellular compartment. ${ }^{38}$ Mitochondria are uniquely susceptible to damage from superoxide, physiologically generated by mitochondrial metabolism. Mitochondrial DNA is substantially more sensitive to oxidative damage than nuclear DNA, as the latter is protected by histones. Also, mitochondria lack the efficient DNA repair mechanisms of the nucleus. Selective damage to mitochondrial DNA by oxidative stress has been implicated in neurodegenerative diseases, espe- cially Parkinson's Disease. ${ }^{39,40}$ Thus, ET might be uniquely involved in the protection of mitochondrial DNA from the superoxide generated in the course of the electron transport cycle.

Appreciation of ET as a physiologic antioxidant augments an already substantial cohort of such agents. Presumably, a multiplicity of diverse antioxidants helps the cell to cope with a wide range of stresses. As already indicated, hydrophilic antioxidants protect soluble proteins whereas lipophilic substances protect lipids. Antioxidant turnover may determine the function. Thus, glutathione turns over very rapidly; with some stressors its levels fall up to $90 \%$ in minutes. Multiple mechanisms exist to regenerate glutathione but, with major tissue insults, these are heavily taxed. The bilirubin-biliverdin cycle provides a means for rapidly regenerating bilirubin after its service as an antioxidant and conversion to biliverdin. The cycle depends on the integrity of the highly abundant biliverdin reductase and can be imperiled if tissue damage impacts this enzyme. ET may afford a more stable mode of cytoprotection. It is not metabolized to any notable extent in mammalian tissues, the half-life of dietary ET being approximately 1 month. ${ }^{38}$ Its cycling between oxidized and reduced sulfur takes place non-enzymatically and is facilitated by the intrinsically tautomeric structure of the molecule. These properties suggest a role for ET as a bulwark, a final defense 
for cells against oxidative damage. Its stability may help mitochondria cope with otherwise overwhelming stresses encountered even during relatively physiologic metabolism.

Evidence that ET is a physiologic antioxidant raises the question of its 'status' in biology. Despite its high concentration and ubiquitous presence, all mammalian ET derives from dietary sources. The existence of ETT establishes ET as an important normal body constituent. In this sense, ET probably fits the definition of a vitamin. Classic criteria require that depletion of a putative vitamin elicit pathological consequences. No pathological syndrome of ET deficiency has been reported. However, lack of such reports may simply reflect the relative dearth of ET research as well as the difficulty of depleting ET. This study implies that ET deficiency can be cytotoxic. Because ET is not metabolized, it slowly exits the body. Moreover, ETT appears to be unidirectional, fostering ET's cellular accumulation, but not its exit. For drug transport, ETT does act in a bidirectional fashion. ${ }^{41}$ Because of its highly charged nature, ET does not readily diffuse out of cells. In our own experiments a variety of cell lines labeled with $\left[{ }^{3} \mathrm{H}\right] \mathrm{ET}$ retain most of the radiolabel for many hours even after repeated washing with fresh media (unpublished data). Mice with targeted deletion of ETT may help elucidate the importance of ET for normal physiology.

In summary, ET is a most unusual amino acid with substantial antioxidant efficacy. The existence of a physiologic ET transporter is responsible for high tissue levels. Depletion of ETT leads to augmented oxidative stress and cell death. ET preferentially protects water-soluble proteins from oxidative damage. The high density of ETT in mitochondria implies a unique role in protecting this organelle from the reactive oxygen species that accumulate even with normal oxidative metabolism. ET also protects the cell from damage induced by reactive nitrogen species and UV radiation (Figure 6). For all these reasons ET appears to be an important physiologic cytoprotectant which probably merits designation as a vitamin.

\section{Materials and Methods}

Cell lines. HeLa cells were obtained from American Type Culture Collection (Manassas, VA, USA) and maintained in Dulbecco's Modified Eagle's Medium containing 10\% fetal bovine serum, L-glutamine and Pen-Strep (Invitrogen, Carlsbad, CA, USA).

Depletion of the ergothioneine transporter ETT. The siRNA for human ETT RNAi was obtained from Santa Cruz Biotechnology Inc. Transfection of HeLa cells was carried out using Lipofectamine 2000 and OptiMEM I (Invitrogen) as per the manufacturer's recommendations. Knockdown of the ETT was confirmed by RT-PCR $72 \mathrm{~h}$ post-transfection, using the SuperScript One-Step RT-PCR Kit (Invitrogen) on $500 \mathrm{ng}$ total RNA isolated using TriZOL Reagent (Invitrogen). The sequence of the primers used for RT-PCR were the following: GAPDH forward 5'-ACTGGCGTCTTCACCACCAT-3', reverse 5'-TACAGCAACAGGGTGTGGA-3'; Human ETT forward $5^{\prime}$-GTCTACCTGTCCACCGTCGT-3' and reverse $5^{\prime}$-TGT GGTGGTTCATTCCTGAA-3'. The size of the RT-PCR products of GAPDH and ETT were 724 and $471 \mathrm{bp}$, respectively.

ET uptake assay. The uptake of ET was monitored using $\left[{ }^{3} \mathrm{H}\right]$ ET (Moravek Biochemicals) as described previously. ${ }^{22}$ Briefly, HeLa cells seeded in 6-well plates were preincubated for $20 \mathrm{~min}$ at $37^{\circ} \mathrm{C}$ in transport buffer containing $3 \mathrm{mM} \mathrm{K}_{2} \mathrm{HPO}_{4}$, $1 \mathrm{mM} \mathrm{MgCl}_{2}, 2 \mathrm{mM} \mathrm{CaCl}_{2}, 5 \mathrm{mM}$ D-glucose, $130 \mathrm{mM} \mathrm{NaCl}$ and $20 \mathrm{mM}$ Tris, pH 7.4. After $20 \mathrm{~min}$, the medium was replaced with fresh transport media containing $3 \mu \mathrm{M}$ $\left.{ }^{3} \mathrm{H}\right] \mathrm{ET}$, which was also preincubated at $37^{\circ} \mathrm{C}$ and incubation continued for $60 \mathrm{~min}$. After incubation, the transport was stopped by addition of ice-cold transport medium

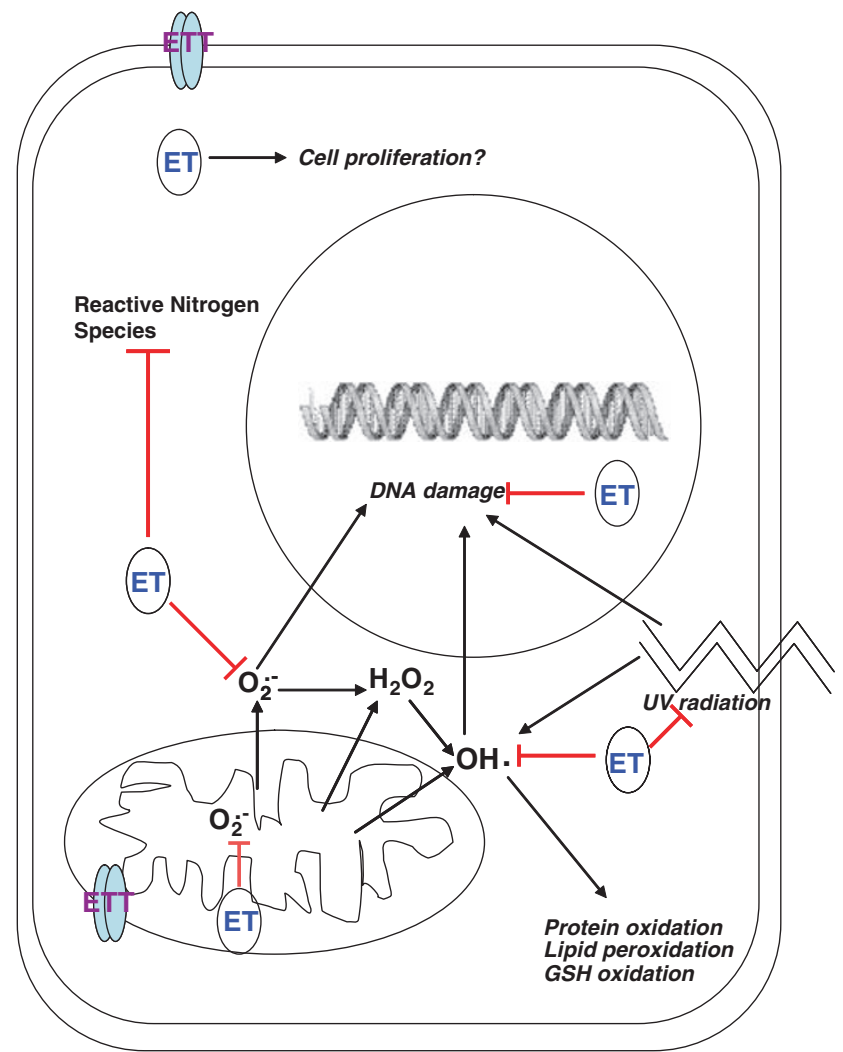

Figure 6 A schematic representation of the cytoprotective actions of ET. Shown is a representation of a eukaryotic cell. ET is accumulated into different cellular compartments via its specific transporter ETT. Reactive oxygen species, viz superoxide $\mathrm{O}_{2}^{-}$, hydroxyl radical $\mathrm{OH}$ generated in the mitochondria by respiration are directly scavenged and blocked (indicated by red lines) by ET, and prevented from damaging cellular components. ET present in the cytoplasm also scavenges these free radicals. ET absorbs UV radiation and prevents DNA breaks and mutations. ET may stimulate certain enzymes involved in antioxidant response and repair mechanisms and also have a role in cell proliferation. In addition, ET protects against a variety of other ROS and reactive nitrogen species providing cytoprotection at multiple levels

followed by three washes with phosphate-buffered saline containing $1 \mathrm{mM}$ EDTA. Cells were then lysed in buffer containing $10 \mathrm{mM}$ Tris, pH 7.4, 0.1\% Triton X-100 and radioactivity measured using a liquid scintillation counter.

Treatments and cell viability assay. Cells were treated with the indicated doses of $\mathrm{H}_{2} \mathrm{O}_{2}$ (Sigma) or Pyrogallol(Fluka) for the designated times and cell viability calculated using 3-(4, 5-dimethylthiazol-2-yl)-2, 5-diphenyltetrazolium bromide (MTT). MTT was added to cell cultures at $125 \mu \mathrm{g} / \mathrm{ml}$ for $60 \mathrm{~min}$. The media was removed and cells were lysed in dimethyl sulfoxide, using an empty well as a blank. Absorbance was read at $570 \mathrm{~nm}$, using $630 \mathrm{~nm}$ as the reference for cell debris.

Protein and lipid oxidation assays. Protein oxidation was determined by measuring protein carbonylation using the OxyBlot Protein Oxidation Detection Kit (Millipore) which uses 2,4-dinitrophenylhydrazine (DNPH) to derivatize oxidize proteins, which can be detected by anti-DNPH antibody. Cells were treated with $0.5 \mathrm{mM} \mathrm{H}_{2} \mathrm{O}_{2}$ for $16 \mathrm{~h}$ in the presence or absence of $1 \mathrm{mM} \mathrm{ET}$ to induce oxidative stress. After the incubation, cells were harvested and protein extracts prepared. Five micrograms of protein was used in the reaction, followed by western blotting. Lipid peroxidation was assessed by measuring the levels of malondialdehyde with the OxiSelect TBARS Assay Kit (Cell Biolabs). Lipid peroxidation was induced in the cell by the Fenton reaction, treating the cells with $30 \mu \mathrm{M} \mathrm{FeSO}_{4}$ and $100 \mu \mathrm{M} \mathrm{H}_{2} \mathrm{O}_{2}$ for $2 \mathrm{~h}$ at $37^{\circ} \mathrm{C}$ 
DNA damage assay. One microgram of supercoiled plasmid DNA was incubated with $2.5 \mathrm{mM} \mathrm{H}_{2} \mathrm{O}_{2}$ and irradiated by UV C on a transilluminator for $5 \mathrm{~min}$. The treated samples were mixed with DNA loading dye and electrophoresed on a $1 \%$ agarose gel to visualize the open circular DNA, which is indicative of DNA damage. To assess mitochondrial DNA (mtDNA) damage, cells were treated with $0.5 \mathrm{mM} \mathrm{H}_{2} \mathrm{O}_{2}$ for $4 \mathrm{~h}$ and total DNA isolated using the Blood Mini Kit (Qiagen). Quantitative real-time PCR was used to determine the extent of mtDNA damage in the region of the D-Loop as described earlier. ${ }^{27}$ The gene $\beta$-actin was used to normalize the data. The primers used for the PCR were: D-Loop Forward: 5'-TATCTTTTGGCGGTATGCACTTTTAACAGT-3' D-Loop Reverse: 5'-TGATG AGATTAGAGTATGGGAGTGG- ${ }^{\prime}$. $\beta$-actin Forward: $5^{\prime}$-TCACCCACACTGTGCCC ATCTACGA-3' $\beta$-actin Reverse: $5^{\prime}$-CAGCGGAACCGCTCATTGCCAATGG- $3^{\prime}$. Standard curves were generated using DNA from untreated control cells and the relative standard curve method was used to analyze data. The results were expressed as the ratio of signal obtained for the $\mathrm{D}$-Loop to that of the signal obtained for $\beta$-actin.

\section{Conflict of interest}

The authors declare no conflict of interest.

Acknowledgements. This work was supported by United States Public Health Service Grants DA00266 (to SHS) and a Research Scientist Award DA00074 (to SHS).

1. Tanret MC. Sur une base nouvelle retiree du siegle ergote, l' ergothioneine. Compt Rende 1909; 49: 22-224.

2. Genghof DS, Van Damme O. Biosynthesis of ergothioneine and hercynine by mycobacteria. J Bacteriol 1964; 87: 852-862.

3. Genghof DS. Biosynthesis of ergothioneine and hercynine by fungi and Actinomycetales. J Bacteriol 1970; 103: 475-478.

4. Melville DB, Eich S, Ludwig ML. The biosynthesis of Ergothioneine. J Biol Chem 1957; 224: 871-877.

5. Askari A, Melville DB. The reaction sequence in Ergothioneine biosynthesis: hercynine as an intermediate. J Biol Chem 1962; 237: 1615-1618.

6. Dubost NJ, Beelman R, Peterson D, Royse DJ. Identification and quantification of ergothioneine in cultivated mushrooms by liquid chromatography-mass spectroscopy. Int J Med Mush 2006; 8: 215-222.

7. Ey J, Schömig E, Taubert D. Dietary sources and antioxidant effects of ergothioneine. J Agric Food Chem 2007; 55: 6466-6474.

8. Melville DB. Ergothioneine. Vitamin Horm 1959; 17: 155-204.

9. Shukla Y, Kulshrestha OP, Khuteta KP. Ergothioneine content in normal and senile human cataractous lenses. Ind Med Res 1981; 73: 472-473.

10. Shires TK, Brummel MC, Pulido JS, Stegink LD. Ergothioneine distribution in bovine and porcine ocular tissues. Comp Biochem Physiol C Pharmacol Toxicol Endocrinol 1997; 117: $117-120$.

11. Hartman PE. Ergothioneine as an antioxidant. Methods Enzymol 1990; 186: 310-318.

12. Grundemann D, Harlfinger S, Golz S, Geerts A, Lazar A, Berkels R et al. Discovery of the ergothioneine transporter. Proc Natl Acad Sci USA 2005; 102: 5256-5261.

13. Tamai I, Yabuuchi H, Nezu J, Sai Y, Oku A, Shimane M et al. Cloning and characterization of a novel pH-dependent organic cation transporter, OCTN1. FEBS Lett 1997; 819: 107-111.

14. Grigat S, Harlfinger S, Pal S, Striebinger R, Golz S, Geerts A et al. Probing the substrate specificity of the ergothioneine transporter with methimazole, hercynine, and organic cations. Biochem Pharmacol 2007; 74: 309-316.

15. Wu X, George RL, Huang W, Wang H, Conway SJ, Leibach FH et al. Structural and functional characteristics and tissue distribution pattern of OCTN1, an organic cation transporter, cloned from placenta. Biochim Biophys Acta 2000; 1466: 315-327.

16. Kobayashi D, Aizawa S, Maeda T, Tsuboi I, Yabuuchi H, Nezu J et al. Expression of organic cation transporter OCTN1 in hematopoietic cells during erythroid differentiation. Exp Hematol 2004; 32: 1156-1162.

17. Tokuhiro S, Yamada R, Chang X, Suzuki A, Kochi Y, Sawada T et al. An intronic SNP in a RUNX1 binding site of SLC22A4, encoding an organic cation transporter, is associated with rheumatoid arthritis. Nat Genet 2003; 35: 341-348.
18. Peltekova VD, Wintle RF, Rubin LA, Amos Cl, Huang Q, Gu X et al. Functional variants of OCTN cation transporter genes are associated with Crohn's disease. Nat Genet 2004; 36 : $471-475$.

19. Taubert D, Jung N, Goeser T, Schömig E. Increased ergothioneine tissue concentrations in carriers of the Crohn's disease risk-associated 503F variant of the organic cation transporter OCTN1. Gut 2009; 58: 312-314.

20. Rahman I, Gilmour PS, Jimenez LA, Biswas SK, Antonicalli F, Aruoma OI. Ergothioneine inhibits oxidative stress and TNF-alpha induced NF-kappa B activation and interleukin-8 release in alveolar epithelial cells. Biochem Biophys Res Commun 2003; 302: 860-864.

21. Maeda T, Hirayama M, Kobayashi D, Miyazawa K, Tamai I. Mechanism of the regulation of organic cation/carnitine transporter 1 (SLC22A4) by rheumatoid arthritis-associated transcriptional factor RUNX1 and inflammatory cytokines. Drug Metab Dispos 2007; 35: 394-401.

22. Nakamura T, Sugiura S, Kobayashi D, Yoshida K, Yabuuchi H, Aizawa S et al. Decreased proliferation and erythroid differentiation of K562 cells by siRNA induced depression of OCTN1 (SLC22A4) transporter gene. Pharm Res 2007; 24: 1628-1635.

23. Taubert D, Grimberg G, Jung N, Rubbert A, Schömig E. Functional role of the $503 F$ variant of the organic cation transporter OCTN1 in Crohn's disease. Gut 2005; 54: 1505-1506.

24. Sedlak TW, Saleh M, Higginson DS, Paul BD, Juluri KR, Snyder SH. Bilirubin and glutathione have complementary antioxidant and cytoprotective roles. Proc Natl Acad Sci USA 2009; 106: 1571-1576.

25. Lamhonwah AM, Tein I. Novel localization of OCTN1, an organic cation/carntine transporter to mammalian mitochondria. Biochem Biophys Res Commun 2006; 345: 1315-1325.

26. Sanchez-Cespedes M, Parrella P, Nomoto S, Cohen D, Xiao Y, Esteller M et al. Identification of a mononucleotide repeat as a major target for mitochondrial DNA alterations in human tumors. Cancer Res 2001; 61: 7015-7019.

27. Mambo E, Gao X, Cohen Y, Guo Z, Talalay P, Sidransky D. Electrophile and oxidant damage of mitochondrial DNA leading to rapid evolution of homoplasmic mutations Proc Natl Acad Sci USA 2003; 100: 1838-1843.

28. Govan III HL, Valles-Ayoub Y, Braun J. Fine-mapping of DNA damage and repair in specific genomic segments. Nucleic Acids Res 1990; 18: 3823-3830.

29. Jennerwein MM, Eastman A. A polymerase chain reaction-based method to detect cisplatin adducts in specific genes. Nucleic Acids Res 1991; 19: 6209-6214.

30. Carlsson J, Kierstan MPJ, Brocklehurst K. Reactions of L-ergothioneine and some other aminothiones with $2,2^{\prime}$-and $4,4^{\prime}$-dipyridyl disulphides and of L-ergothioneine with iodoacetamide. 2-Mercaptoimidazoles, 2- and 4-thiopyridones, thiourea and thioacetamide as highly reactive neutral sulphur nucleophils. Biochem J 1974; 139: 237-242.

31. Obayashi K, Kurihara K, Okano Y, Masaki H, Yarosh DB. L-Ergothioneine scavenges superoxide and singlet oxygen and suppresses TNF-alpha and MMP-1 expression in UV-irradiated human dermal fibroblasts. J Cosmet Sci 2005; 56: 17-27.

32. Aruoma OI, Spencer JP, Mahmood N. Protection against oxidative damage and cell death by the natural antioxidant ergothioneine. Food Chem Toxicol 1999; 37: 1043-1053.

33. Deiana M, Rosa A, Casu V, Piga R, Assunta Dessí M, Aruoma Ol. L-ergothioneine modulates oxidative damage in the kidney and liver of rats in vivo: studies upon the profile of polyunsaturated fatty acids. Clin Nutr 2004; 23: 183-193.

34. Colognato R, Laurenza I, Fontana I, Coppedé F, Siciliano G, Coecke S et al. Modulation of hydrogen peroxide-induced DNA damage, MAPKs activation and cell death in $\mathrm{PC} 12$ by ergothioneine. Clin Nutr 2006; 25: 135-145.

35. Markova NG, Karaman-Jurukovska N, Dong KK, Damaghi N, Smiles KA, Yarosh DB. Skin cells and tissue are capable of using L-ergothioneine as an integral component of their antioxidant defense system. Free Radic Biol Med 2009; 46: 1168-1176.

36. Doré S, Takahashi M, Ferris CD, Zakhary R, Hester LD, Guastella D et al. Bilirubin, formed by activation of heme oxygenase-2, protects neurons against oxidative stress injury. Proc Natl Acad Sci USA 1999; 96: 2445-2450. Erratum in: Proc Natl Acad Sci USA 1999;96:10944.

37. Baranano DE, Rao M, Ferris CD, Snyder SH. Biliverdin reductase: biliverdin reductase: a major physiologic cytoprotectant. Proc Natl Acad Sci USA 2002; 99: 16093-16098.

38. Kawano H, Otani M, Takeyama K, Kawai Y, Mayumi T, Hama T. Studies on ergothioneine. VI. Distribution and fluctuations of ergothioneine in rats. Chem Pharm Bull (Tokyo) 1982; 30: $1760-1765$

39. Simon DK, Lin MT, Zheng L, Liu GJ, Ahn CH, Kim LM et al. Somatic mitochondrial DNA mutations in cortex and $\mathrm{s}$ ubstantia nigra in aging and Parkinson's disease. Neurobiol Aging 2004; 25: 71-81.

40. Lin MT, Beal MF. Mitochondrial dysfunction and oxidative stress in neurodegenerative diseases. Nature 2006; 443: 787-795.

41. Yabuuchi H, Tamai I, Nezu J, Sakamoto K, Oku A, Shimane M et al. Novel membrane transporter OCTN1 mediates multispecific, bidirectional, and pH-dependent transport of organic cations. J Pharmacol Exp Ther 1999; 289: 768-773. 